\title{
Plague of Icy Breath. Cholera and the Gateshead Community 1831-1832*
}

Ellen Tullo

\section{Summary}

The impact of cholera epidemics on communities around the world during the 19th century has generated a vast array of resources for the medical historian. However, the more readily available testimonies of doctors and local boards of health dominate the literature, whilst our understanding of the experience of individuals, particularly the destitute victims of cholera and their families, is sparse. This article analyses a collection of unpublished documents assembled by an antiquary, John Bell, from Gateshead, North-East England, in 1831-1832, in order to reconstruct the experience of the local community as they prepared themselves for the arrival of cholera and how they responded to its devastating effects. The paper concludes by examining the enduring changes prompted by the community reaction to the cholera outbreak of 1831-1832, including the establishment of the Gateshead Dispensary.

Keywords: cholera; epidemic; Gateshead; dispensary movement

\section{Introduction}

The Pestilence is nearing

To England's merry shore:

A million ghosts appearing

Beckon a thousand more. ${ }^{1}$

Elizabeth Barrett Browning aptly communicates the nervous anticipation that abounded across England as cholera relentlessly extended its path

* This paper was adapted from a postgraduate MA in the History of Medicine at the University of Newcastle upon Tyne. I would like to thank my supervisor, Dr Thomas Rütten, who has offered ongoing patient support and invaluable advice, and Dr David GardnerMedwin for directing me to the John Bell collection. Material from the collection is quoted with permission of the Librarian, Robinson Library, Newcastle University.

1 Elizabeth Barrett Browning 1832, "The Pestilence” (McCarthy 1955).

Ellen Tullo, 7 Cleghorn Street, Heaton, UK-Newcastle NE6 5DJ (ellentullo@doctors.net.uk). 
from the Ganges Delta towards Western Europe. Cholera, confined to India until 1817, then began to expand its range to neighbouring countries $^{2}$. En route for the West, the first cholera pandemic was halted in Astrakhan and Europe breathed a sigh of relief. In 1829, however, cholera fought harder; by the beginning of October 1831, the port of Hamburg in Germany, in regular contact with the trading ports of England, succumbed to the disease. England watched, waited and worried. Despite a number of pre-emptive decisions made by a newly formed Central Board of Health aiming to halt the impending arrival ${ }^{3}$, on 23rd October 1831 England's first case of cholera was confirmed in the North-East city of Sunderland; the victim was a keelman, William Sproat ${ }^{4}$. From its establishment in this region, cholera would come to relentless creep across England, eventually visiting frightened communities the length and breadth of the country. The arrival of cholera in England inspired a huge number of publications on the topic, largely compiled by the medical profession and government authorities. The causes, prevention and treatment of cholera were subject to controversy and were furiously debated in such literature. Nonetheless, the medical profession and the authorities largely agreed on one feature of the illness - in common with many of the diseases of the nineteenth century, cholera wreaked its most devastating effects on those living in poverty and destitution ${ }^{5}$. As such, the history of cholera has been described as offering a «unique opportunity» for the historian to understand more about the lives of a broad segment of the nineteenth-century population, particularly the working classes ${ }^{6}$. Whilst the testimony of doctors and local boards of health have been widely available to the historian, there have been fewer sources apparent that explicitly shed light on the experience of individuals, particularly the destitute victims of cholera and their families 7 . This paper aims to reconstruct local lay experience of cholera in 1831-1832 in a discrete area of the North-East, Gateshead, in the context of the national reaction to the arrival of cholera. The key primary source used to focus on the Gateshead community in the midst of cholera is the John Bell collection, held by Newcastle University Robinson Library. The collection is comprised of a large number of unpublished documents including letters, Board of Health committee minutes, handbills, posters, and demographic information on cholera victims relevant to the out-

2 Pollitzer 1959, 17-21.

3 Brockington 1961, 162-170.

4 Morris 1976, 11.

5 Smith 1979, 231; Evans 1988, 128-130.

6 McGrew 1960, 64.

7 Morris 1976, 80f. 
break in Gateshead in 1831-1832, drawn together by a local bookseller and antiquary $^{8}$. These documents were examined with a view to uncovering more about the lesser reported experience of the victims of cholera, and their reaction to this startling and unprecedented threat. The paper is divided into three sections, firstly exploring how the community members prepared themselves for the impending threat of cholera and how they chose to interpret the nature the anticipated threat. The second part concentrates on the experience of those individuals suffering from the symptoms of cholera, and the way in which the community as a whole reacted to the decisions made by the local medical profession and the Gateshead Board of Health to combat the disease. The paper lastly examines the enduring changes prompted by community reaction to the cholera outbreak of 1831-1832, including the establishment of the Gateshead Dispensary.

\section{The approach of cholera - Gateshead 1831}

The town of Gateshead in 1831, separated from the adjacent city of Newcastle-upon-Tyne by the river, was made up of a «semi-rural» community of approximately 15000 inhabitants 9 . St Mary's church, considered the «spiritual centre» of Gateshead, played an important role in the administration and welfare of the parish ${ }^{10}$. Led by the Rector John Collinson, a man held in high esteem by the Gateshead community ${ }^{11}$, the parish council was responsible for

8 Robinson Library Special Collections, Newcastle University (hereafter RL), RB 616.932 BEL, 1832. John Bell (1783-1864) was born in Newcastle. His father, also called John, was a local land-surveyor and bookseller - see Isaac, Peter, "Bell, Thomas (1785-1860)", Oxford Dictionary of National Biography. Online edition (Oxford 2004). From childhood Bell was described as «a voracious collector of all things», particularly antique books and items of local interest; see http://www.asaplive.com/FARNE/Learn.cfm?ccs=288\&cs=507. In 1803 Bell ceased to work in his father's bookshop and set up his own second-hand bookshop on Newcastle Quayside - see http://www.oxforddnb.com/view/article/2028/52628?docPos=9. His interests inspired him to publish a number of books and pamphlets of local poems and songs and in 1813, with the backing of the Duke of Northumberland, Bell was instrumental in setting up the Newcastle Society of Antiquaries. A list of John Bell's publications is recorded in Welford 1895, 236-238. Sadly John Bell's passion could not keep his business afloat; he was declared bankrupt in 1817 and many of his possessions were sold. His attention moved to Gateshead where he practised as a land-surveyor alongside his brother Thomas whilst continuing his own private collections of numerous books and manuscripts. One of these unpublished compilations, Collections Relative to the Cholera at Gateshead, was sold to a book collector, Robert White, who eventually donated the documents to the University of Newcastle - see http://www.ncl.ac.uk/library/specialcollections/collection details.php?id $=50$.

9 Manders 1980, 18.

10 Manders 1980, 137.

11 Lumley 1932, 45. 
the allocation of community funds and the care of the poor citizens of Gateshead ${ }^{12}$. The living conditions for many families in Gateshead mirrored the appalling poverty evident throughout England's industrial towns and cities. James Adair Lawrie, a Scottish military doctor who visited a number of North-East towns, including Gateshead in 1831, described the conditions that he had witnessed:

[...] the poorer part of the community dwell in narrow, overcrowded, filthy streets and lanes, built on the low banks of the Wear and Tyne, and in Sunderland and Newcastle the richer classes live in well-aired houses, built on elevated ground, which rises by a steep ascent from the rivers. In Gateshead the population is principally composed of labourers, and in all parts of it, narrow, ill-aired streets and alleys abound..$^{13}$

Such winding, narrow streets and precariously built housing inevitably led to damp, ill-ventilated and overcrowded residences. The mainstay of the water supply to Gateshead was a reservoir on Gateshead Fell from which water was piped $^{14}$. The majority of the community had no access to private supplies of water piped to their homes; instead they relied on the public street fountains or «pants» ${ }^{15}$. Waste disposal in Gateshead was particularly deficient; the first sewage pipe built in 1773 was practically obsolete; raw waste ran down the main streets and into the Tyne, further polluting this water source ${ }^{16}$. It was towards this vulnerable environment of deprivation and urban filth that the cholera of 1831 was approaching.

In an attempt to pre-empt the arrival of cholera from Europe and limit its impact, by the summer of 1831 The Privy Council of England had established a Central Board of Health, headed by Henry Halford, President of the Royal College of Physicians ${ }^{17}$. The role of the Board was to devise an anticipatory strategy to deal with the looming threat of cholera and to disseminate these ideas across England. With cholera hovering menacingly across the North Sea in Hamburg, the Central Board decided that each area of the country should contribute to the attempts to prevent cholera by setting up local Boards of Health, consisting of «[...] the chief and other magistrates, the clergymen of the parish, two or more physicians or medical practitioners, and three or more of the principle inhabitants $[\ldots] »^{18}$. Gateshead Parish, alongside communities the length and breadth of England, heeded the advice; on 26th October 1831 a group of residents met in order to inaugurate the Gateshead Board of Health

12 Mackenzie 1827, 758.

13 Lawrie 1832, 15.

14 Rennison 1977, 184.

15 Rennison 1977, 179.

16 Manders 1980, 177f.

17 Brockington 1961, 162.

18 Privy Council 1831, 4. 
under the leadership of John Dobson ${ }^{19}$. Soon after the establishment of local Boards, the authority of the original Central Board of Health was marred by internal disagreement and mistrust; in November 1831 the original committee was disbanded and a new Central Board of Health set up at Whitehall ${ }^{20}$. It was to this new Central Board that the local Boards would report. In accordance with the proposed membership of a local Board of Health, the Gateshead Board was comprised of John Collinson, local surgeons, physicians and well-known citizens of Gateshead ${ }^{21}$. The first set of committee minutes of the Gateshead Board of Health lists their intentions ${ }^{22}$. Firstly, the Board would take steps to try to prevent the arrival of cholera by assessing and improving the sanitary conditions of Gateshead. The Parish would be divided into discrete districts, and a sub-committee of two or three Board members would be responsible for inspecting and improving the conditions of their district, and reporting their findings to the Board ${ }^{23}$. Secondly, aware of the deprivation prevalent in many areas of the Parish, the Board aimed to fortify the community by setting up a soup kitchen and paying for a stock of material provisions such as blankets, cloaks and petticoats that were to be distributed ${ }^{24}$. In anticipation of the arrival of cholera, already demonstrating its propensity to provoke chaos down-river, the third intention of the Gateshead Board of Health, as suggested by the Central Board, was to identify a suitable site for a cholera hospital in the Parish ${ }^{25}$. The residents of Gateshead would be encouraged to voluntarily report any symptoms of cholera at the earliest opportunity ${ }^{26}$; patients would then be directed to the hospital in order to isolate them and try to prevent the spread of this unpredictable malady. The hospital setting would allow patients to be monitored by medical practitioners who would be given the opportunity to treat their symptoms, whilst learning more about this new disease and the way in which it behaved. The Board initially proposed that an edifice in the Gateshead poorhouse should be reserved for this purpose ${ }^{27}$. The plan was challenged by the Guardians of the poorhouse

19 RL, RB 616.932 BEL, Volume 1, Gateshead Board of Health Committee Minutes, 26 Oct. 1831.

20 Durey 1979, 25.

21 RL, RB 616.932 BEL, Volume 2, List of Gateshead Board of Health Members, undated.

22 RL, RB 616.932 BEL, Volume 1, Gateshead Board of Health Committee Minutes, 26 Oct. 1831.

23 RL, RB 616.932 BEL, Volume 1, Poster - At a Meeting of the Committee Appointed to Cooperate with the Churchwardens and Overseers of the Poor of Gateshead, 27 Oct. 1831.

24 RL, RB 616.932 BEL, Volume 2, District 1 Committee Report, 29 Nov. 1831.

25 Privy Council 1831, 4.

26 RL, RB 616.932 BEL, Volume 1, Poster - Caution Respecting Cholera, undated.

27 RL, RB 616.932 BEL, Volume 2, Gateshead Board of Health Committee Minutes, 8 Nov. 1831. 
who objected on the basis that cholera would be likely to spread swiftly through the overcrowded environment ${ }^{28}$. Establishing a suitable venue for a cholera hospital would prove to be a challenge for the Gateshead Board of Health; the visiting Dr Lawrie reported that the Board «long failed» to find even a house that could provide suitable care for cholera victims ${ }^{29}$.

The Gateshead Board of Health committee minutes largely document the thoughts and actions of those in charge of implementing policy. However, decisions needed to be communicated to the residents of Gateshead. John Bell's collection of documents reveals a number of examples of interaction between Board and community. News of the establishment of the Gateshead Board of Health and their proposed pre-emptive action was communicated to the lay population by means of printed wall posters that were displayed in the streets (fig. 1). At a time when books and newspapers were too expensive for

Fig. 1. RL, RB 616.932 BEL, Volume 1, Poster - Caution Respecting Cholera, undated.

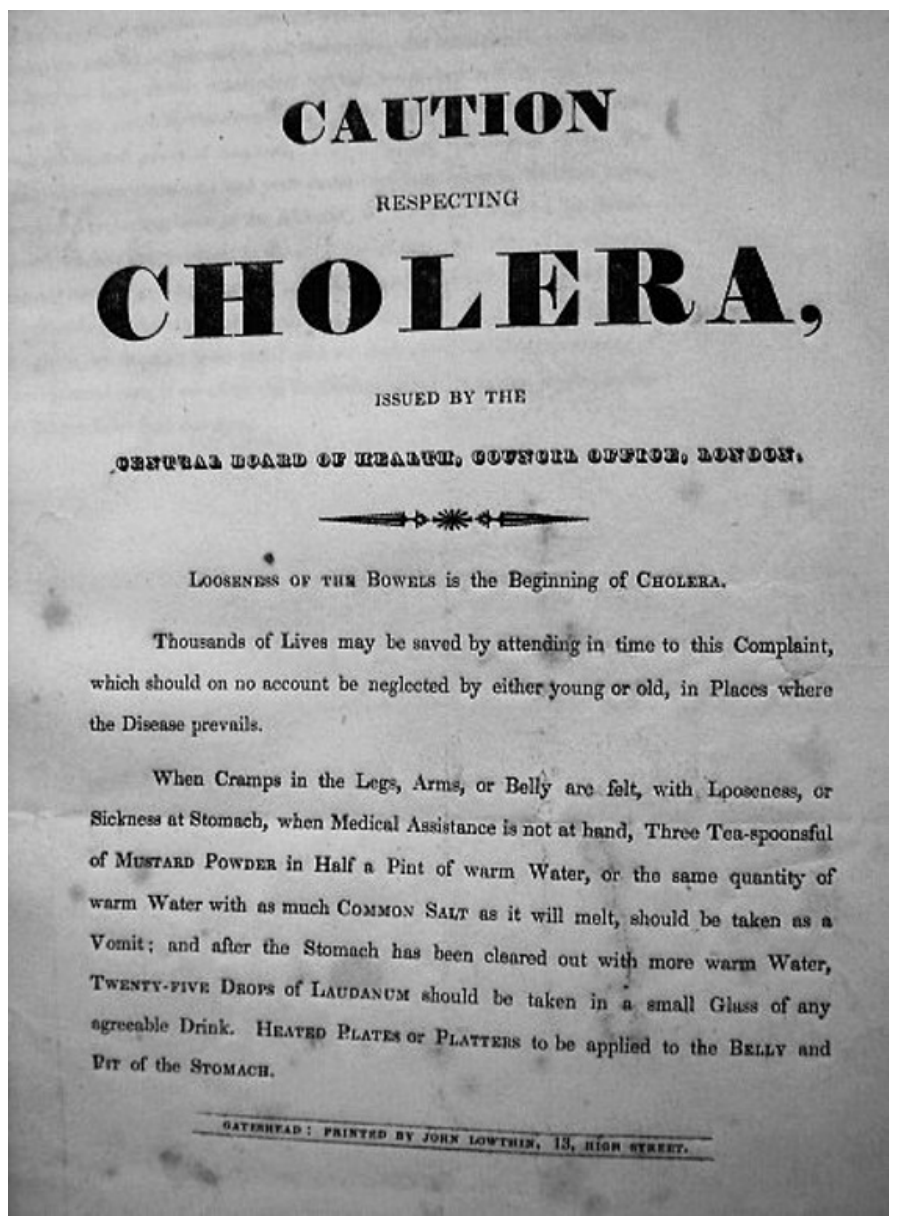

28 RL, RB 616.932 BEL, Volume 1, Letter from the Churchwardens and Overseers to Gateshead Board of Health, 16 Dec. 1831.

29 Lawrie 1832, 26. 
the average laboure ${ }^{30}$, such street literature constituted an important source of information. It is difficult to accurately determine the public reaction in Gateshead as the community absorbed the news of the coming threat. Did reading the posters displaying information on the newly created Board of Health, assembled to fight cholera, provoke anxiety or a sense of reassurance that matters were under control? ${ }^{31}$ How did the community respond to the suggestions made by the Board that energetic cleansing of the streets and houses of Gateshead would protect them from cholera? Certainly, some of the proposed measures devised by local Boards were nearly impossible to implement on the budget of an average laboure ${ }^{32}$. To fully reconstruct the likely range of emotion provoked in the lay community by the threat of cholera in Gateshead is not feasible; however, the reports of the Board district sub-committees who visited people in their homes do allow fleeting insight into the reactions of some individuals to the Board's advice. Inspectors found that Gateshead inhabitants had responded variably to the advice given to clean their streets and houses. Clearly some had taken the recommendations to heart - the inspectors of district 4 reported: «We are happy to find that lime wash had in many instances being [sic] applied to the inside of the houses already $[\ldots] \aleph^{33}$. For other residents such voluntary action was made virtually impossible by daily domestic struggles. In the same district, an inspector observed in one house «[...] one of the children confined to Bed with sickness, with scarcely any Bed or Bedding $[\ldots] »^{34}$. For some families the imminent threat of cholera must have seemed like yet one more concern to add to their list of difficulties. This abstract new risk may not have provoked the immediate prompt to action that the Board of Health had hoped. Aside from those who could not respond to the Board's advice, there were others who simply would not. At a second visit to «Pipe House Entry», district inspectors found the house to be «[...] in the same state as before ... Mr Andrews pays no attention to our applications to him ${ }^{35}$. It remains difficult to be certain as to why residents might have chosen to ignore the advice of the Board; lack of funds, lack of time or simple laziness are possibilities, but interaction between Board officials and the community may also have prompted a level of antagonism that prevented residents from following their advice. Contemporary medical scandals such as Burke and Hare's body-snatching,

30 Hollis 1970, 12.

31 Durey 1979,160 , suggests that the posters and placards were a source of stress rather than comfort for the poor, who were often unable to carry out the requests made of them.

32 Smith 1979, 233.

33 RL, RB 616.932 BEL, Volume 2, District 4 Second Committee Report, 25 Nov. 1831.

34 RL, RB 616.932 BEL, Volume 2, District 4 Second Committee Report, 25 Nov. 1831.

35 RL, RB 616.932 BEL, Volume 2, District 4 Second Committee Report, 25 Nov. 1831. 
alongside ongoing squabbling amongst the medical profession, had provoked a culture of mistrust of medical practitioners and health policy ${ }^{36}$. Many of the Gateshead Board inspectors were medical practitioners; it is possible that local residents felt particularly suspicious of these enquiries into their personal circumstances and were therefore unwilling to co-operate. Certainly, one of the inspectors recognised that his advice to clean up personal property had the potential to cause offence and cultivated a more circumspect and tactful approach:

[...] at the east end of the church walk there should be a wall built to confine the midden within bounds, for it is usually spread over so great an extent as to be very offensive - it is recommended that the secretary do intimate the above remarks with those of the other committees, (in the least offensive manner possible) to the respective proprietors. ${ }^{37}$

Although these district reports show that Board advice was followed in some circumstances, policy was not always smoothly implemented, and tensions were apparent between Board and community. Further friction would arise as the Parish debated the causes and thus the most appropriate defence against the emerging cholera.

Despite energetic and often acerbic debate amongst medical professionals on the causes of cholera, no single theory held sway for the majority of either the medical practitioners or the lay population. Cholera, like many other diseases, prompted explanations based on the natural and supernatural, on internal humoral disruption and external environmental factors, all of which did not necessarily exist in direct opposition to each other ${ }^{38}$. For the medical profession and the government, perhaps the most widely discussed cholera polemic was the issue of whether the disease was contagious or not. To state that two distinct positions, «contagionist» and «anticontagionist», existed in direct opposition to each other would be an oversimplification; as is well known, the debate on the contagiousness or otherwise of cholera was more complicated ${ }^{39}$. Even the very terms used to discuss this controversy were defined «variously and vaguely» ${ }^{40}$. Medical publications on cholera usually made it quite clear whether the author was in favour of contagion or not; less clearly discernable was the attitude held by the lay population to the causes of cholera ${ }^{41}$. In the absence of a convincing medical explanation for the

36 Richardson 1989, 223; Durey 1979, 103f.; Evans 1988, $138 f$.

37 RL, RB 616.932 BEL, Volume 2, District 3 Committee Report, 9 Dec. 1831.

38 Bynum 1994, 67.

39 Pelling 1978, 2-31.

40 Hamlin 1998, 60.

41 Although, some authors have suggested that the poor tended towards believing cholera to be contagious: Durey 1979, 157; Winslow 1980. 
emerging cholera, inevitably many looked to a supernatural theory to explain what was happening. In 1831 the majority of the population believed in the role of Providence to some degree; accordingly diverse explanations were offered as to the religious significance of cholera and how man might have sinned in order to invoke such a punishment ${ }^{42}$. Some religious leaders preached that to contract cholera was evidence of personal moral failure ${ }^{43}$, whilst other religious groups chose to explain the cholera pandemic as a sign of mankind's universal mis-management of God's earth; communal neglect and squalor had invited the disease into society ${ }^{44}$. At a national level special prayers were promoted, offered specifically to save communities from the coming pestilence. Indeed Gateshead received such an offering; John Bell's collection contains an example of a prayer, published in London and sent to John Collinson ${ }^{45}$. On the one hand, religious explanations of cholera and advice to spend time in prayer may have had a calming effect on a community on the verge of panic ${ }^{46}$. On the other hand, religious leaders were presented with the opportunity to take advantage of the alarm generated by cholera in order to berate people for their immoral behaviour. One of the seemingly immoral habits attacked by religious leaders was the consumption of alcohol. In Gateshead, as in many English towns, the public house provided a social retreat and informal meeting place for the community ${ }^{47}$. For poor labourers the attractions of the public house included warmth, comfort and social stimulation $^{48}$, but by the 1820 s advocates of abstinence had drawn force, and pressure was mounting to denounce insobriety and promote temperance ${ }^{49}$. As cholera loomed close in 1831, religious institutions preached a link between the sin of intemperance and likelihood of contracting cholera. Medical practitioners also linked cholera to alcohol; drinking was said to weaken the constitution of an individual - cholera did not result directly but that individual would be increasingly pre-disposed to contracting the illness ${ }^{50}$. In Gateshead, alcohol emerged as a significant theme amongst the explanations offered for the establishment of cholera in the town. When cholera chose to strike at the end of December 1831, a Newcastle newspaper remarked that the outbreak «[...] has been attributed, and we believe with truth, to the dele-

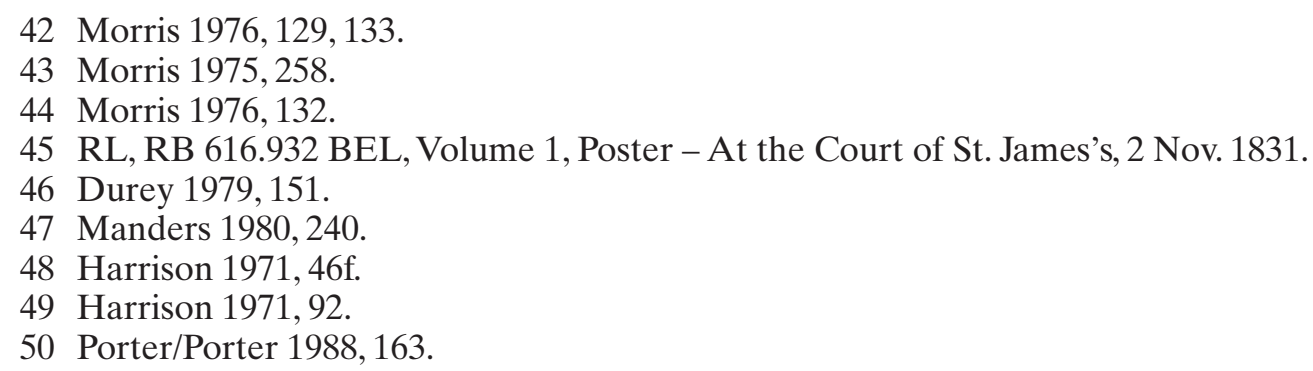


terious practice of drinking spirits at this particular season by the lower classes $»^{51}$. Later, a local pamphlet entitled An Affectionate Address chastised the community for their indulgence of immoral vices, including drinking, the implication being that Gateshead citizens had brought the ravages of cholera upon themselves ${ }^{52}$.

\section{The arrival of cholera}

On 15th December 1831 Mr Henry Brady, a Gateshead surgeon and member of the Board of Health, was called to attend to Mrs Mary Hindmarsh, aged 55, who was «quite bad with vomiting and sickness $»^{53}$. According to the testimony of her husband Joseph, which reveals much about the couple's illness behaviour and beliefs, Mary began to feel unwell after eating some cold pease pudding on the 11th. She quickly took to her bed, and over the next few days Joseph watched as she steadily deteriorated. Eventually Mary had «lost all power, and could not help herself, and then she got upon the bed and she fell all down upon the bed $\aleph^{54}$. In desperation Joseph firstly called upon his neighbours, before turning to the Gateshead medical professionals for help ${ }^{55}$. Despite the attempts of Mr Brady to alleviate Mary's suffering, her condition worsened and she died on the evening of 15th December. The surgeons were unanimous in their diagnosis: Mary Hindmarsh had died of cholera ${ }^{56}$. The Board of Health duly reported the case to Whitehall ${ }^{57}$, whilst in Gateshead investigations began into how Mary might have contracted the disease. Joseph Hindmarsh was questioned about Mary's whereabouts and behaviour prior to her illness. To supplement the income of her husband, a blacksmith, Mary «went about buying and selling» ${ }^{58}$. To the Gateshead Board of Health it was particularly significant

51 Newcastle Courant, 31 Dec. 1831. National papers also drew attention to the apparent link between alcohol consumption, considered particularly excessive in Newcastle and Gateshead, and the outbreak of cholera - see The Times, 31 Dec. 1831.

52 Anon. 1832, 3.

53 RL, RB 616.932 BEL, Volume 2, Examination of Joseph Hindmarsh or Hymers, 30 Dec. 1831.

54 RL, RB 616.932 BEL, Volume 2, Examination of Joseph Hindmarsh or Hymers, 30 Dec. 1831.

55 Once the diagnosis of cholera had been made, Joseph Hindmarsh's neighbours feared the possibility of contagion and he was asked to leave his lodgings. His ordeal was later reported in the national press - see The Times, 6 Jan. 1832.

56 RL, RB 616.932 BEL, Volume 1, Gateshead Board of Health Committee Minutes, 16 Dec. 1831.

57 RL, RB 616.932 BEL, Volume 1, Gateshead Board of Health Committee Minutes, 26 Dec. 1831.

58 RL, RB 616.932 BEL, Volume 1, Gateshead Board of Health Committee Minutes, 16 Dec. 1831. 
that she «would take a Glass of Beer» and «occasionally she would take Spirits ${ }^{59}$; it was judged by the medical practitioners that Mary's demise was related to her habits, considered «depraved in the extreme» ${ }^{60}$.The timing of her death was significant; in the run up to Christmas and New Year, the Board of Health knew that festivities would be accompanied by enthusiastic consumption of alcohol. In an attempt to curb the perceived potentially damaging effect of inebriation, the Board tried to modify the behaviour of the community by threatening to fine publicans for evidence of any drunken persons found at their establishment ${ }^{61}$. It remains uncertain as to whether the community heeded the advice; it seems that at least some of the Gateshead residents were determined to celebrate Christmas in the traditional way, cholera or no cholera $^{62}$. The authors of An Affectionate Address heaped scorn amongst those who turned the message on its head and defiantly continued «[...] drinking to keep the cholera away» ${ }^{63}$. For those who believed alcohol to be a significant factor in the promulgation of cholera, an explosion of cases in Gateshead on Christmas day seemed to confirm their predictions ${ }^{64}$. After Mary Hindmarsh's death on 15th December the disease had seemingly behaved with ominous patience, but by Boxing Day it had unleashed its full force. As Mr Brady recalled, «on the 25th about one o'clock we were assailed by a third and fourth example of the disease, and before the next morning at 10 o'clock, very considerable numbers have fallen sacrifice to its pestilential ravages $»^{65}$. The work of the Gateshead Board of Health had truly begun.

The symptoms of cholera came on rapidly and violently; an individual might find him- or herself well in the morning, and moribund by evening. It is difficult to adequately comprehend the experience of patients and families affected by cholera since few direct testimonies are available. As an alternative source, doctors' case notes, whilst written from the point of view of a medical professional rather than a patient, reflect an interaction between two parties and retain the potential to shed light on patient experience ${ }^{66}$. The notes of practitioners in Gateshead reveal that attending to cholera patients and witnessing their suffering was shocking, even for the hardiest of doctors. Thomas Molison, a doctor from Edinburgh who travelled to Gateshead in

59 RL, RB 616.932 BEL, Volume 1, Gateshead Board of Health Committee Minutes, 16 Dec. 1831.

60 Greenhow 1832, 129.

61 RL, RB 616.932 BEL, Volume 1, Poster, Justice Room, 31 Dec. 1831.

62 Longmate 1966, 47.

63 Anon. 1832, 5.

64 Durey 1979, 116.

65 Greenhow 1832, 130.

66 Smith 1979, 10. 
order to learn more about cholera, said, «I was, if possible, still more struck by the awfully appalling character of the symptoms [...]. I have seen a good deal of suffering in my time, but none has equaled or approximated to this» ${ }^{67}$. Despite the distressing workload that he was faced with, Molison listened attentively to the accounts of his patients in order to alleviate their fears: «To give confidence to my patients, I often sat for half an hour upon the bed, familiarly conversing with them ${ }^{68}$. Molison was one of numerous medical practitioners to attend to cholera patients in Gateshead. Despite long periods of exposure to and physical contact with sufferers, it was noted by these practitioners that none of them, or the nurses working in the cholera hospital, had contracted the disease ${ }^{69}$. The conspicuous absence of cholera in practitioners was highlighted as evidence against contagion by those who held anti-contagionist views ${ }^{70}$. The community too picked up on this anomaly but explained it differently; rather than evidence against contagion, the resistance of practitioners was understood by the community to be indicative of the importance of maintaining a positive attitude rather than giving in to fear. A handbill written by «an inhabitant» in nearby Durham, a copy of which is enclosed in John Bell's collections, advises fellow residents:

Every one knows how seldom Doctors take any disorder from the sick persons whom they visit, and the great reason of this is, because they are not afraid: they are used to the way of sickness, and therefore it does not so much alarm them. To be cheerful and active therefore, to go about our common business and our common amusements, and to think as little about the Cholera as possible, would be very means of keeping us safe from it. ${ }^{71}$

It seems that there was not only variation in the understanding of cholera between different doctors, but that diverse forms of rationalisation were adopted by the lay and the medical communities as a whole; each group looked to a model of health and disease that explained the behaviour of cholera in terms that they were familiar with.

The treatments offered by Gateshead practitioners to the community were the same as those available nationally. At the onset of illness, instead of turning immediately to medical practitioners for help, families were likely to initially look to their own home recipes and remedies. In anticipation of cholera, Gateshead families were advised to bolster their stock of medicines ${ }^{72}$; calomel, ammonia and laudanum were widely recommended and utilised.

67 Molison 1832, 28.

68 Molison 1832, 26.

69 White 1832, 8.

70 Greenhow 1832, 100.

71 Anon. 1831, 7.

72 Lawrie 1832, 92f. 
Various medicinal preparations, and objects such as «cholera belts», were advertised in local newspapers as possessing the power to prevent the disease ${ }^{73}$. Once cholera arrived, it became clear to doctors and patients that there was no obviously effective remedy. Doctors, however confidently they might promote their own expertise, were able to offer little more to patients than the household stock. They continued to employ additional physical therapies such as bloodletting and warm applications but to no avail ${ }^{74}$. Despite working diligently, doctors' inability to relieve symptoms made for a poor impression of professional medicine in general ${ }^{75}$. Whilst doctors generally attended patients at home, the arrival of cholera saw the emergence of venues acting as specialised cholera hospitals. In preparation, the Central Board of Health had advised each local Board to identify a building where patients might be isolated in order to try to prevent spread of disease. Following their initial difficulties in locating a suitable site for a cholera hospital, the Gateshead Board of Health eventually appropriated an edifice in the yard of the Gateshead Poor House and appointed a lead nurse ${ }^{76}$. When the number of cholera cases soared after 25th December, medical practitioners worked around the clock to look after the victims ${ }^{77}$. James Lawrie reported that some nurses even slept alongside their patients ${ }^{78}$. The hospital experience for the cholera victims themselves is difficult to reconstruct. Certainly for the lay population in general, hospitals at the time were regarded with fear and suspicion ${ }^{79}$. The poorest members of any community were likely to lack adequate space to be able to isolate sick family members at home or the money to pay for private nursing. Thus during a cholera outbreak, it was the poor, consenting or otherwise, that were most likely to be removed to a hospital. Interestingly, in contrast to evidence of the deep suspicion on the part of the lay population reported in secondary literature on cholera, a proportion of the Gateshead community seemed keen to attend the cholera hospital. In a letter to Colonel Creagh, a Newcastle official, John Collinson remarked upon the satisfaction of the Gateshead residents, «[...] the striking proof of which is the applications for

73 Newcastle Courant, 17 Dec. 1831.

74 For a summary of the pharmacological and physical methods used by a Gateshead surgeon see J. Fife 1831, 3-17.

75 Morris 1976, 162.

76 RL, RB 616.932 BEL, Volume 1, Letter from John Dobson to the Central Board of Health, 7 Jan. 1832.

77 Accepting that the medical professionals of Gateshead were overstretched by their workload, a Times correspondent criticised the Board of Health over their poor choice of venue for the cholera hospital. An underestimation of the number of beds required meant that the Board had failed to help relieve the pressure on the medical professionals visiting patients at home: see The Times, 4 Jan. 1832.

78 Lawrie 1832, 12.

79 Morris 1976, 103. 
admission to the Hospital have been more numerous than our accommodations $[\ldots]\rangle^{80}$. It is possible, of course, that Collinson's remark merely reflects the desperate living conditions and terrible suffering that left poor residents with no choice but to apply to the hospital. His statement may not be concrete evidence of genuine optimism and trust on behalf of the victims of cholera, yet his letter implies that, in Gateshead at least, any hostility towards the medical practitioners did not act as a barrier to hospital attendance. It seems that popular suspicion of hospitals was to some degree appeased in Gateshead during the acute outbreak of cholera.

By 12th January 1832 cholera cases had abated sufficiently enough for the Board of Health to dismiss the medical practitioners of their duties at the cholera hospital ${ }^{81}$. New diagnoses of cholera continued to occur in the parish, but the acute explosion had passed and the number of cases plateaued. Of the 36 victims treated at the Gateshead cholera hospital, 21 died $^{82}$. The hospital mortality rate, significantly higher than the approximate rate of 50 percent in the community ${ }^{83}$, did not go unnoticed by local medical practitioners. With the benefit of twenty-first century scientific understanding of cholera as an infectious disease, it is possible to surmise that this higher mortality rate was the result of, amongst other factors, insanitary practices and procedures within the hospital. In the absence of such knowledge a Gateshead doctor, Thomas Greenhow, came to an alternative conclusion: «It appears unquestionable, therefore, that to the delay in the use of remedies, and the unavoidable disturbance and fatigue attendant on the removal of patients, we must attribute the less favourable results of hospital treatment» ${ }^{84}$. Given the contemporary understanding of disease, Greenhow's explanation for the hospital mortality rate was a reasonable interpretation, based on his own experience of treating the sick. But no matter which explanation was offered for mortality rates, Gateshead was left with numerous deceased and the associated problems of how to deal with their bodies.

Confusion over the contagiousness or otherwise of cholera led the medical and political authorities to fear that the corpses of cholera victims might act as vectors in the spread of disease. The normal death rituals, as practised by lay communities across England, were discouraged during the cholera outbreak as they involved prolonged contact with the corpse ${ }^{85}$. Instead, families

80 RL, RB 616.932 BEL, Volume 1, Letter from Collinson to Creagh, 8 Jan. 1832.

81 RL, RB 616.932 BEL, Volume 1, Gateshead Board of Health Committee Minutes, 12 Jan. 1832.

82 Greenhow 1832, 122.

83 Morris 1975, 12.

84 Greenhow 1832, 123.

85 For a discussion of lay burial rituals see Richardson 1989, 3-20. 
were directed to new procedures designed to limit any potential risk, many of which were at odds with traditional rituals ${ }^{86}$. Similarly, the Gateshead Board of Health recommended that:

[...] the Bodies of Persons who may die of Cholera should be enclosed in a Coffin well pitched and interred within 12 hours after death, and that all communication between the living and the dead be prevented as much as possible. That the graves shall be six feet deep and in a particular part of the Church Yard to the North West of the Church, and that about two Balls of quick lime be thrown into each grave, and where practicable a quantity to be put into each Coffin. ${ }^{87}$

Such recommendations ran roughshod over the meticulous cleansing and purifying rituals which formed an important part of the grieving process. In some areas of England the administrative directions of local Boards of Health inflamed public emotion and families refused to report cases of cholera lest they be forced to abandon traditional rituals ${ }^{88}$. In addition to hostility towards enforced directions for burial, some authorities in England further incensed the public by allowing doctors to perform post-mortem examination on cholera victims. Doctors' desire to dissect cholera bodies added insult to the injury of draconian burial procedures, and local rumour even emerged that cholera victims were too hastily pronounced dead, then dissected or buried whilst still alive ${ }^{89}$. The Gateshead Board showed themselves to be aware of this sensitive issue and chose not to risk antagonising the community by performing post-mortem dissections locally. Greenhow, a member of the Board, recalled the advice of Colonal Creagh in Newcastle, offered in order to avoid public protest over dissection: «The lower class in Gateshead have been very much on the alert upon the subject, so that hitherto nothing has been done $»^{90}$. The conduct of the Gateshead Board of Health appears to have helped avoid the type of extreme reaction to cholera seen in other parts of the country, where opposition to burial procedures coupled with popular suspicion of doctors led to rioting ${ }^{91}$.

At the beginning of February of 1832 a lull in the number of new cases of cholera led the Gateshead Board to conclude that the disease had abated. The Board wrote a letter to Whitehall to inform them of the good news and received a jubilant reply congratulating them on their efforts ${ }^{92}$. Sadly their

86 Morris 1976, 104.

87 RL, RB 616.932 BEL, Volume 1, Gateshead Board of Health Committee Minutes, 18 Dec. 1831. For a more detailed account of burial directions see Fife 1831,34-6.

88 Watts 1997, 195.

89 Baird 1832, 7; Morris 1976, 168.

90 Greenhow 1832, 128.

91 Richardson 1989, 227. For a detailed discussion of the factors contributing to rioting in Liverpool, including opposition to burial procedure and dissection, see Burrell/Gill 2005.

92 RL, RB 616.932 BEL, Volume 2, Letter from MacClean to the Gateshead Board of Health, 8 Feb. 1832. 
joy proved to have been premature; a cluster of new cases at the end of February and the beginning of March demonstrated cholera's resilience. April, May and June of 1832 saw a second lull before another increase in new cases in July ${ }^{93}$. St Mary's Parish records note the burial of the last victim of cholera, on 5th November $1832^{94}$. From the beginning of the outbreak in December 1831, it was more than 10 months until Gateshead was reprieved.

\section{Aftermath of cholera}

Collecting robust cholera statistics for the epidemic of 1831-1832 in any area of England is not an easy task; several factors complicate the compilation and analysis of mortality and morbidity statistics ${ }^{95}$. Before 1837 , there was no regulated national civil registration of life events such as births and deaths ${ }^{96}$, thus the estimation of deaths due to any one cause is difficult. During outbreaks of disease such as cholera, lack of clear diagnostic criteria led to confusion in differentiating, and thus counting, cases of cholera in the midst of numerous other endemic gastrointestinal diseases ${ }^{97}$. Since medical professionals encouraged the treatment of any signs of diarrhoea as early cholera, it is quite possible that a number of cases of endemic gastrointestinal disease that improved with treatment were subsequently counted as resolved cases of cholera ${ }^{98}$. Whilst this diagnostic inaccuracy may have led to an overestimate in number of cases of cholera, a number of other factors conversely suggest that morbidity and mortality statistics for cholera were actually more likely to have been an underestimate ${ }^{99}$. Although the Central Board of Health encouraged local Boards such as Gateshead to submit regular summaries to Whitehall, the accuracy of the data collected depended on the consistent reporting of new cases of cholera by community members. As discussed, patients and their families had a number of potential reasons not to cooperate, including hostility towards the medical professionals attempting to intervene, fear of cholera hospitals, and unpopular enforced burial procedures. Under-

93 Clephan $1854,6$.

94 Gateshead Central Library (hereafter GCL), 1832.

95 Morris 1976, 81.

96 Woods/Woodward 1984, 21.

97 An objective method of diagnosing cholera would not become available until the identification of the cholera bacillus by Robert Koch in the 1880s, and the implementation of techniques allowing confirmation of a bacterial illness according to Koch's criteria. See Watts $1997,172$.

98 Morris 1976, 166.

99 Morris 1976, 12. 
estimates of cholera cases are likely to be most pronounced for working-class patients ${ }^{100}$. In towns and villages where cholera simultaneously struck down a large number of people, medical professionals were hard-pressed to attend to all of the sick - it is likely that the collecting of accurate statistics was less of a priority than attempting to keep people alive. The overall statistical impact of cholera in England was not as significant as the number of deaths from endemic diseases such as TB, measles and influenza, and yet it is acknowledged that the popular reaction to cholera was disproportionate in its vigour ${ }^{101}$. The alarming and unpredictable nature of the disease terrified communities; the possibility of sudden explosions of cases, as had occurred in Gateshead, heightened emotions and exacerbated tensions in towns across England. Depersonalised mortality and morbidity statistics can thus only go so far in helping to reconstruct the effect of cholera on a community.

Despite the limitations of interpreting cholera data John Bell's documents, in conjunction with other local sources, allow estimates of morbidity and mortality in Gateshead to be made. The Gateshead Board's decision to divide the parish into districts with appointed lead inspectors aided the co-ordination of responding to and monitoring new cases within each district. Each head of district reported back to the Board, which collated summative information on the number of sick patients, the number of deaths and the number of recoveries. The information from each individual district was accumulated and simplified in the form of a «daily report», a copy of which was sent to the Central Board in London. Copies of the daily reports in John Bell's collection can be used to illustrate the course taken by the disease in the first two months after its emergence in December of 1831. The last days of December 1831 and the early days of January 1832 saw the highest increase of new cases of cholera per day, slowing to a plateau by mid-January. The number of deaths largely follows this pattern, with the highest death rates at the end of December 1831 . The data collected by local Boards nationally and centralised by Whitehall tended only to record time and place of death rather than specific demographics ${ }^{102}$. Alongside the daily reports, however, John Bell's collection contains a list of the names of cholera patients, the district that they resided in and their age. The data derived from this list allow an illustration to be constructed of the way in which cholera differentially affected each age group within the community (fig. 2). The majority of endemic diseases in England at this time disproportionately affected the very young (under 5) and

100 For an analysis of cholera cases by social class see Morris 1976, 87-93.

101 O'Connor 2000, 32.

102 Morris 1976, 79. 
the very old (over 50) ${ }^{103}$. Cholera was noted to behave differently; instead of targeting the extremes of age, the disease also affected the middle ages and was thus more economically damaging than endemic disease. The data from Gateshead support this epidemiological pattern - the graph shows that the largest number of cases was seen in the age groups 35-39 and 40-44. John Bell's documents only contain records of deaths until March of 1832 and thus cannot be used to calculate the total number of deaths from cholera in Gateshead throughout the whole of the epidemic of 1831-1832. However, the work of a Gateshead journalist, James Clephan, calculated the total mortality from cholera in the community by using St Mary's and St John's Parish records as sources. According to Clephan, between December 1831 and November 1832, a total of 234 residents of Gateshead died of cholera and were buried there ${ }^{104}$. On the one hand, a total cholera mortality of 234 in an estimated population of 15000 may not seem devastating; other settlements along the Tyne lost a far greater proportion of residents, most notably New-

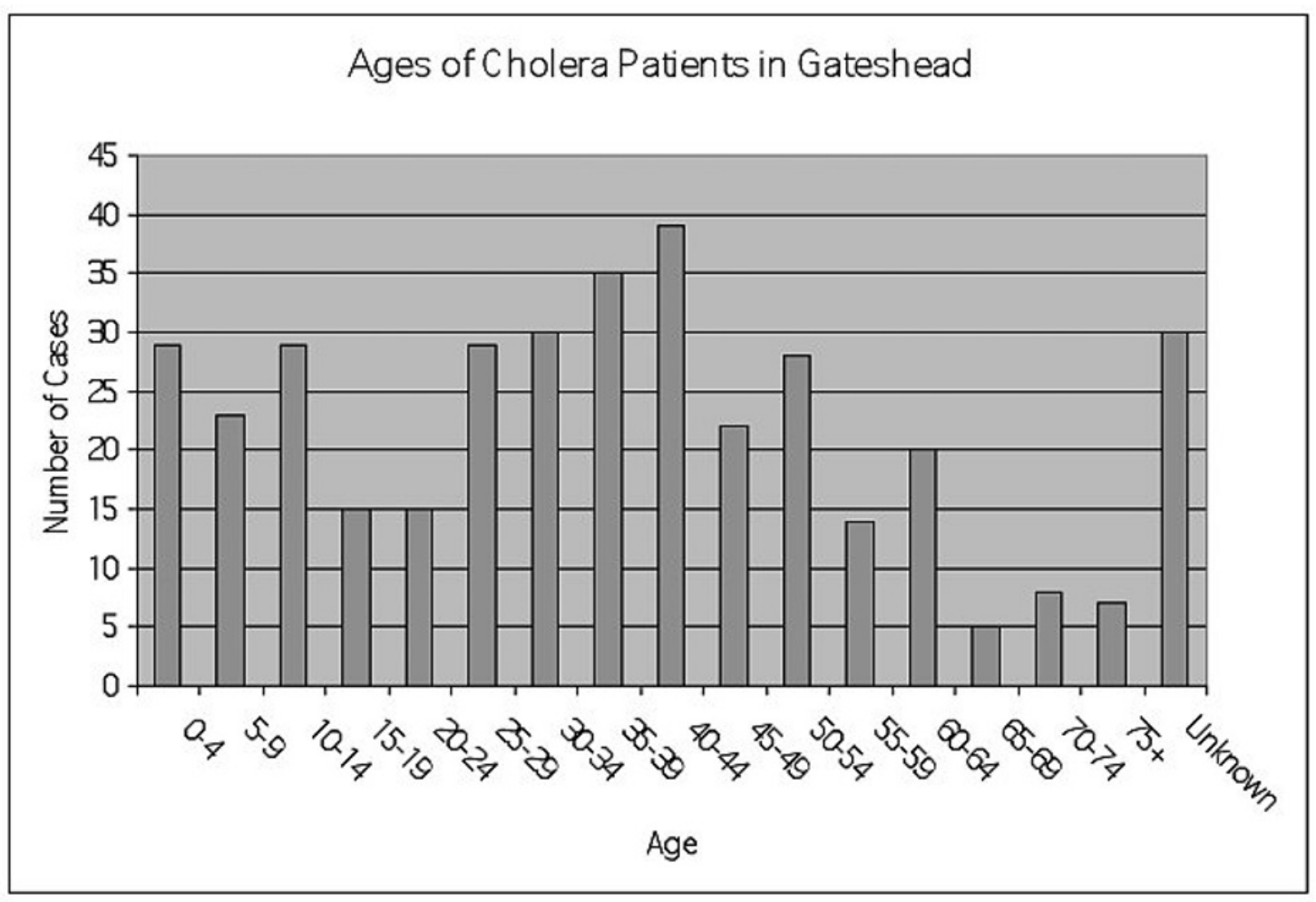

Fig. 2. Data derived from a list of cholera patients contained within RL, RB 616.932 BEL, Volume 1.

103 For a graphic illustration of the probability of death by age in the nineteenth century see Woods/Woodward 1984, 23.

104 Clephan 1854, 5f. 
burn where 55 of the 550 residents died ${ }^{105}$. On the other hand, the manner in which the deaths occurred in Gateshead must have been exceptionally alarming for the community. An earlier graph has been used to illustrate the rate of new cases and deaths in the first days of cholera in Gateshead. The reality of so many deaths in a short space of time for families, practitioners and religious leaders must have been grim; in just two days, 27th and 28th December, the officials of St Mary's church conducted 39 burials of Gateshead residents ${ }^{106}$. The sudden deaths in Gateshead did not go unnoticed nationally. Cholera's emergence in the North-East meant that the rest of England looked to the region for developments. The first issue of the Cholera Gazette, produced by the Central Board of Health, chose to publish the alarming number of burials in Gateshead in December of 1831, alongside the comparative data for 1830 , to make a point ${ }^{107}$. The bare numerical figures of cholera data, however, cannot adequately communicate the experience of those affected by cholera. It must be born in mind that the well-known index case of Mary Hindmarsh was just one fleeting example of those 234 Gateshead residents who died of cholera, each would have had their own individual story to tell.

The emergence of cholera in December 1831 brought to light the conspicuous absence of any community institution with the facilities to supply patients with the recommended forms of treatment for cholera. The cholera hospital and its team of nurses and medical practitioners did not possess the capacity to both tend to and distribute medicines to all of the sick. Whilst posters implored the community to be alert to early diarrhoea, at that time believed to precede fully blown cholera ${ }^{108}$, there was no established system in place for patients to respond to such premonitory symptoms. On 28th December 1831 a public meeting was held to discuss how this deficiency might be overcome. Two men, W. H. Burkett and J. Charlton, are said to have raised the possibility of opening a Gateshead Dispensary ${ }^{109}$. The «Dispensary Movement», beginning in the eighteenth century, had already seen the establishment of a number of these philanthropic institutions across England ${ }^{110}$. Although a dispensary had opened in Newcastle in 1751, in 1832 Gateshead still had no such facility. The idea was popular; those at the meeting signed a petition which was delivered to John Collinson ${ }^{111}$. A second public meeting

105 Morris 1976, 62.

106 Clephan 1854, 6.

107 The Cholera Gazette, No. 1, 31 Dec. 1831.

108 RL, RB 616.932 BEL, Volume 1, Poster, Important Caution, 3 Mar. 1832.

109 Fallow 1932, 3.

110 Louden 1981,324f.

111 Fallow 1932, 3. 
was scheduled for 3rd February 1832 in order to discuss the practicalities of establishing the Gateshead Dispensary ${ }^{112}$. Following the meeting, the laudable aims of the dispensary were published in the form of a broadsheet, such that the community might be kept informed of this new development:

[...] it is the opinion of this meeting that the establishment of a Dispensary in this town would not only most essentially assist in ameliorating and preserving the public health, but by placing medicine and advice within the reach of the poor, tend to prevent the appearance of disorders similar to that by which this neighbourhood has so lately suffered. ${ }^{113}$

The dispensary would be staffed by a team of health professionals:physicians, surgeons and, most importantly, an apothecary. At the end of March, from five suitably qualified applicants, Mr Francis Bennett was elected apothecary ${ }^{114}$; he began working in April once a suitable site for the dispensary was located on Gateshead High Street ${ }^{115}$. Both the staff working at the dispensary and the patients that attended were expected to fulfil strictly defined roles, set out in the form of rules drawn up by the Dispensary Committee ${ }^{116}$. The apothecary was the lynchpin of the institution; his duties included the purchasing and dispensing of medicines to patients attending the establishment, but also visiting the sick in their homes and monitoring their progress. Patients might access the dispensary through a number of channels. Wealthy residents of Gateshead who donated money to the dispensary had the power to «recommend» a number of patients each year ${ }^{117}$. Such a selection procedure aimed to help the «deserving» poor of the community - those considered virtuous enough to have their illness treated in order that they might return to work ${ }^{118}$. Without recommendation, emergency «casualties» might also be attended at the discretion of the medical staff. In addition the dispensary was also equipped to provide a Cow Pox inoculation service for children in the community. Attending patients were expected to adhere to a strict code of conduct; failure to attend appointments on time or to behave «decently and soberly» was punished by dismissal from the dispensary ${ }^{119}$. Once individuals were relieved of their illness, it was expected that they formally thank

112 RL, RB 616.932 BEL, Volume 1, Poster, Public Meeting, 1 Feb. 1832.

113 Tyne and Wear Archive Service (hereafter TWAS) HO/GD/11/1, Broadsheet, Dispensary in Gateshead, undated.

114 TWAS, HO/GD/11/1, Gateshead Dispensary Committee Minutes, 26 Mar. 1832.

115 Fallow $1932,5$.

116 TWAS HO/GD/11/1 1832, Second Annual Report of the Gateshead Dispensary, with the Rules, and a List of the Officers and Subscribers, 6-11.

117 TWAS HO/GD/11/1 1832, Second Annual Report of the Gateshead Dispensary, with the Rules, and a List of the Officers and Subscribers, 5.

118 Louden 1981, 330.

119 TWAS HO/GD/11/1 1832, Second Annual Report of the Gateshead Dispensary, with the Rules, and a List of the Officers and Subscribers, 5. 
their patrons and attend church to give «grateful thanks to Almighty God for their cure» ${ }^{120}$. Dispensary Committee Minutes show that patients had begun to attend the dispensary by May of $1832^{121}$. The running of the dispensary continued smoothly throughout the months of May and June when cholera remained at bay. In July, as new cases emerged, the medical staff struggled to meet their obligations. At a meeting on 17th July 1832 it was noted that:

The Apothecary to the Gateshead Dispensary having represented to the Committee that, in consequence of the numerous recent applications for relief in Diarrhoea and in some instances in Spasmodic Cholera, he is unable to pay that attention to his Patients which their situation requires. ${ }^{122}$

The Committee resolved to appoint an assistant to aid the apothecary for the following months whilst cholera continued to afflict the community and vex medical practitioners.

The arrival of cholera in Gateshead had prompted the founding of a dispensary that would go on to serve the patients of the future. The community had responded to the arrival of the disease by improving the range of medical resources available to them. Not only did the dispensary help to alleviate established cases of cholera, it aimed to prevent similar outbreaks in the future. According to the Dispensary Committee, the venture was considered an unparalleled success. The first annual report of the institution thanked and congratulated those who had donated money:

The Committee of the Gateshead Dispensary, in presenting their report of the proceedings of that Institution to the first Anniversary Meeting, trust they may be allowed to express the proud satisfaction which they feel in having to congratulate the subscribers on the complete realisation of their benevolent and liberal intentions, in behalf of the invalid poor of the District; for never, in the records of Charity, was Philanthropy more opportunely exerted - never more triumphantly successful - than in the establishment of the Dispensary in Gateshead. ${ }^{123}$

Although the Dispensary Committee were clearly proud of their achievement, it is more difficult to determine how patients felt about the service that they received there. Certainly patients continued to demonstrate their satisfaction indirectly by continuing to attend in ever-increasing numbers. The institution would persist in providing an outpatient service, significantly contributing to the public health of the Gateshead community, for decades to come. For all the insurmountable horrors that cholera had wrought, its arrival had also highlighted health-care deficiencies and thus provoked action to improve medical facilities for the residents of Gateshead.

120 TWAS HO/GD/11/1 1832, Second Annual Report of the Gateshead Dispensary, with the Rules, and a List of the Officers and Subscribers, 11.

121 TWAS, HO/GD/11/1, Gateshead Dispensary Committee Minutes, 22 May 1832.

122 TWAS, HO/GD/11/1, Gateshead Dispensary Committee Minutes, 17 Jul. 1832.

123 TWAS, HO/GD/11/1, First Annual Report of the Gateshead Dispensary, 5. 


\section{Conclusion}

Thou canst not live amongst us,

Oh plague of icy breath,

Our torrid sun hath flung us

Shields from the cold blue death. ${ }^{124}$

By the end of 1832 Gateshead had successfully weathered the storm of cholera: 234 victims lay cold in their graves, whilst hundreds more had experienced the violent symptoms of the disease. Those lucky enough to have avoided cholera were likely to have witnessed the suffering and death of others; many grieved for family and friends. Lest the victims be forgotten, John Collinson erected a memorial in St Edmund's church to remind the community of what had come to pass ${ }^{125}$. The authority of the Gateshead Board of Health had been transitory; after the cholera epidemic subsided, the Board disbanded, although many of the key members continued to work to improve the health of the community through the newly established dispensary. Sadly, the visitation of 1831-1832 was not an isolated event; cholera swept back through the North-East in 1849 during the second English epidemic, and again for the third time in 1852. Despite an ever-increasing medical and political interest in improving public health, the dreadful urban living conditions experienced by residents in Gateshead, and in many other towns across England, failed to advance significantly. The residents remained, for a time, as vulnerable to endemic and epidemic disease as prior to the first outbreak of cholera. John Bell's Collections contain an abundant range of documentation and images offer an opportunity to explore the impact of cholera on a local community. Although John Bell's documents, like many other collections, are weighted towards the testimony of those literate representatives in positions of power, the diverse origin of the documents nevertheless offer opportune glimpses into the lives of poor victims and their families. From the respected members of Gateshead Board to the wretched Mary Hindmarsh, John Bell's collection identifies and brings to life the characters that were irreversibly affected by the epidemic. It is impossible to know whether John Bell ever envisaged that his collection would, almost two hundred years later, offer so inviting a prospect as to be able to look back to 1831-1832 to witness the experience of a community facing up to the challenge of cholera.

124 Elizabeth Barrett Browning 1832 (McCarthy 1955, 224).

125 Lyall circa 1920, 38. 


\section{Bibliography}

Abbreviations

GCL Gateshead Central Library

RL Robinson Library Special Collections, Newcastle University

TWAS Tyne and Wear Archive Service

\section{References}

Anon., An Inhabitant. Address to the Inhabitants of this Town about the Cholera Morbus (Durham 1831)

- An Affectionate Address to the Inhabitants of Newcastle and Gateshead on the Ravages of the Spasmodic Cholera. Intended as a Warning Voice, Especially to Persons in the Habits of Intemperance, Sabbath-Breaking, and Lewdness. Being the Characters who have Chiefly Suffered Thereby, of Which Many Striking Facts are here Adducted (Newcastle 1832)

Baird, D., Substance of a Lecture on Cholera, Read Before a Meeting of the Medical Profession of Liverpool on Wednesday, the 18th January 1832 (London 1832)

Brockington, Fraser, «Public health at the Privy Council 1831-1834», Journal of the History of Medicine and Allied Sciences 16 (1961) 161-185

Burrell, Sean/Geoffrey Gill, «The Liverpool cholera epidemic of 1832 and anatomical dissection - medical mistrust and civil unrest», Journal of the History of Medicine and Allied Sciences 60 (2005) 478-498

Bynum, William F., Science and the Practice of Medicine in the Nineteenth-Century (Cambridge 1994)

Clephan, James, The Three Warnings. Or, Facts and Figures of the Cholera Epidemics of Gateshead (London 1854)

Durey, Michael, The Return of the Plague. British Society and the Cholera 1831-1832 (Dublin 1979)

Evans, Richard J., «Epidemics and revolutions. Cholera in nineteenth-century Europe», Past and Present 110 (1988) 123-146

Fallow, H. F., Gateshead Dispensary Centennial Souvenir 1832-1932. A Brief Retrospect (Gateshead 1932)

Fife, James, Practical Remarks on the Continental Cholera, Containing Extracts from the Latest Works of Eminent Medical Men, who have Treated the Disease in India, Russia, Poland, and Prussia. With a Corrected Translation of the Report of the Polish College, a Short Appendix, for the General Reader, and a Postscript on the Report of the Government Medical Commission (Newcastle 1831)

Gateshead Central Library, Register of Burials in the Parish of St Mary's Gateshead 1832

Greenhow, Thomas M., Cholera, as it Has Recently Appeared in the Towns of Newcastle and Gateshead. Including Cases Illustrative of its Physiology and Pathology, with a View to the Establishment of Sound Principles of Practice (London 1832)

Hamlin, Christopher, Public Health and Social Justice in the Age of Chadwick. Britain 1800-1854 (Cambridge 1998)

Harrison, Brian H., Drink and the Victorians (London 1971)

Hollis, Patricia, The Pauper Press. A Study in Working-Class Radicalism of the 1830s (London 1970)

Isaac, Peter, «Bell, Thomas (1785-1860)», Oxford Dictionary of National Biography. Online edition (Oxford 2004)

Lawrie, James A., Essay on Cholera, Founded on the Observations of the Disease in Various Parts of India, and in Sunderland, Newcastle, and Gateshead, with Notices of the Treatment, and of the Civil and Hospital Police Adopted in these Towns (Glasgow 1832)

Longmate, Norman, King Cholera. The Biography of a Disease (London 1966)

Louden, Irvine, «The Origins and Growth of the Dispensary Movement in England», Bulletin of the History of Medicine 55 (1981) 322-342 
Lumley, D., The Story of Gateshead Town. From the Earliest Age to the Mid-Victorian (Newcastle 1932)

Lyall, A.C., Old Gateshead (Gateshead circa 1929)

Mackenzie, Eneas, A Descriptive and Historical Account of the Town and County of Newcastle upon Tyne, Including the Borough of Gateshead, Volume 2 (Newcastle 1827)

Manders, Frank W. D., A History of Gateshead (Gateshead 1980)

McCarthy, Barbara P., «The Pestilence. By Elizabeth Barrett Browning», Notes and Queries 2 (1955) $223 f$.

McGrew, Roderick E., «The first cholera epidemic and social history», Bulletin of the History of Medicine 34 (1960) 61-73

Molison, Thomas, Remarks on the Epidemic Disease called Cholera, as it Occurred in Newcastle (Edinburgh 1832)

Morris, Robert J., «Religion and medicine. The cholera pamphlets of Oxford», Medical History 19 (1975) 256-270

- Cholera 1832. The Social Response to an Epidemic (London 1976)

O'Connor, Erin, Raw Material. Producing Pathology in Victorian Culture (Durham 2000)

Pelling, Margaret, Cholera, Fever and English Medicine, 1825-1865 (Oxford 1978)

Pollitzer, Robert, Cholera (Geneva 1959)

Porter, Roy/Dorothy Porter, In Sickness and in Health. The British Experience 1650-1850 (London 1988)

Privy Council, Rules and Regulations Proposed by the Board of Health for the Purpose of Preventing the Introduction and Spreading of the Disease Called Cholera Morbus in this Country, with an Account of the Symptoms and Treatment of the Said Disease, and Ordered by a Committee of the Lords of His Majesty's most Honourable Privy Council, at Whitehall, the 20th October 1831 (London 1831)

Rennison, R. W., «The Supply of Water to Newcastle upon Tyne and Gateshead, 1680-1837», Archaeologia Aeliana 5 (1977) 179-196

Richardson, Ruth, Death, Dissection and the Destitute (London 1989)

Robinson Library Special Collections, Newcastle University, RB616.932 BEL, Collections Relative to the Cholera at Gateshead, in the County of Durham, 1831, Volumes 1 and 2

Smith, Francis B., The People's Health 1830-1910 (London 1979)

Watts, Sheldon H., Epidemics and History. Disease, Power and Imperialism (New Haven 1997)

Welford, Richard, Men of Mark 'Twixt Tyne and Tweed, Volume 1 (London 1895)

White, David B., Hints on the Practicability of Contracting the Extension and Greatly Diminishing the Fatality of the Malignant Cholera. With Practical Remarks upon the most Successful Plans of Treatment hitherto Adopted in this Country. In a Letter to the Rev. J. Collinson (Newcastle 1832)

Winslow, Charles-Edward A., The Conquest of Epidemic Disease. A Chapter in the History of Ideas (Baltimore 1980)

Woods Robert/John Woodward, Urban Disease and Mortality in Nineteenth Century England (London 1984)

\section{Newspapers}

The Cholera Gazette

The Newcastle Courant

The Times

Websites

http://www.asaplive.com/FARNE/Learn.cfm?ccs $=288 \& \operatorname{cs}=507$

http://www.ncl.ac.uk/library/specialcollections/collection_details.php?id=50 